\title{
Preparation and characterization of polymer composites based on charge-transfer complex of phenothiazine-iodine in polystyrene
}

\author{
R A SINGH*, R K GUPTA and S K SINGH \\ Department of Chemistry, Faculty of Science, Banaras Hindu University, Varanasi 221 005, India
}

MS received 29 November 2003; revised 30 May 2005

\begin{abstract}
Polymer composites based on charge-transfer complex of phenothiazine and iodine with polystyrene have been prepared in different weight ratios and characterized by FTIR, XRD, mechanical, microstructure and electrical properties (d.c. as well as a.c.). These composites show semiconducting behaviour as the conductivity increases with increasing temperature. Low percolation threshold (10\% wt CTC) has been found indicating that processable conducting polymers with improved mechanical properties can be prepared by this method.
\end{abstract}

Keywords. Phenothiazine-iodine; polymer composite; charge-transfer complex; polystyrene.

\section{Introduction}

Molecular electronic materials based on charge-transfer complexes have attracted considerable attention in recent years (Foster 1969; Singh et al 1991; Ashwell 1992). They have unusual electrical, magnetic and optical properties, which could be used in fabrication of devices (Ulanski 1990). However, the mechanical strengths of these materials are very low, which restrict their application (Ashwell 1992). Mechanical strength of these chargetransfer complexes can be improved by preparing their composites with insulating materials (Margolis 1989). Such composite materials have improved mechanical strengths, while retaining their other properties e.g. electrical conductivity, optical and magnetic properties. Such electrically conductive polymer composites have been prepared by using graphite, carbon black, metal powders and flakes as filler into insulating polymer materials (Skotheim 1986). Polymer composites of conductive polymers such as polyacetylene, polypyrrole, polythiophene and polyaniline have also been reported (Yoon et al 1994; Benerjee and Mandal 1995; Omartova et al 1996; Yigit et al 1996).

Highly conductive polymer composites have been prepared by reticulate doping of poly (bisphenyl A carbonate/ propylene carbonate) with micro crystals of charge-transfer materials (Jeszka et al 1981). The room temperature conductivity of this system was found to be $3 \times 10^{-2} \mathrm{~S} / \mathrm{cm}$ at $1 \mathrm{wt} \%$ of the complex. High conductivity in these materials was related to the existence of conducting path due to microcrystallization of the complex in the polymer

*Author for correspondence

(rasingh@bhu.ac.in; rasinghbhu@yahoo.com) matrix. Nano-structured conducting polymer composites of super paramagnetic particles in conducting polymer were studied (Kryszewski and Jeszka 1998). Highly conductive films of poly (vinylidine fluoride) reticulately doped with 2 wt $\%$ of TTF-TCNQ complex having electrical conductivity of about $1 \mathrm{~S} / \mathrm{cm}$ were reported (Choi et al 1990). Generally reticulate growths are obtained at elevated temperature (Srivastava and Singh 2000). So the composite of charge-transfer complexes with iodine as acceptor cannot be made by this method, because iodine may start liberating at high temperature. So, the composite of charge-transfer materials in which iodine is used as acceptor are generally made by two-step reticulate doping (Jeszka and Tracz 1992; Tracz et al 1996) or by solution evaporation or diffusion method at lower temperature, resulting in dispersion type of composite (Kang et al 1994).

We have prepared the composites of phenothiazineiodine with poly (vinyl chloride) (Singh and Srivastava 1999) and poly (vinylacetate) (Srivastava and Singh 2000). It is well established that the properties of a composite are highly dependant on the morphology of the system (Carmono et al 1980). In this paper, we report the morphological dependence of the physical properties of the phenothiazine-iodine charge-transfer complex in polystyrene. The detailed electrical properties of these composites have been studied. Apart from electrical characterization, IR, XRD, microstructure and mechanical properties have also been reported.

\section{Experimental}

Phenothiazine (Aldrich) was used after recrystallization in ethanol and iodine (S.D. Fine-Chem. Ltd.) was used after purification by sublimation from $\mathrm{KI}+\mathrm{I}_{2}$ mixture $(1: 1 \cdot 25)$. The polystyrene (GSC) was used as received. All other 
chemicals used were of AR grade. The phenothiazineiodine $\left(\mathrm{Ptz}-\mathrm{I}_{2}\right)$ complex was prepared by mixing the hot solutions of phenothiazine and iodine (in 1:2 molar ratio) in diethyl ether (Singh et al 1991). For preparation of composites, the required amount of charge-transfer complex (CTC) and polystyrene (PS) was dissolved in benzene separately and mixed together. The solvent was evaporated at room temperature. The fine powders of the composites were pressed in pellets in a hydraulic press under 8 tonnes load.

The d.c. measurements were done with the help of a Source-Measure Unit (Keithley model-236). The a.c. measurements were done on LCZ meter (Keithley model3330). Platinum was used as contact for all the measurements. The microstructures were obtained from Lietz Labour Lux-D, XRD patterns were recorded with the help of diffractional X-ray diffractometer using $\mathrm{CuK}_{\alpha}$ radiation, IR spectra were recorded on FTIR (Jasco-5300) and mechanical strengths by Instron Universal Testing Machine.

\section{Results and discussion}

\subsection{Physical nature}

The physical nature of the composite was confirmed by IR and XRD studies. The IR spectra of phenothiazine have broad band between 3320 and $3380 \mathrm{~cm}^{-1}$ corresponding to weakly acidic $\mathrm{N}-\mathrm{H}$ in the cation radical of phenothiazine (Singh et al 1991). Similarly IR spectra of polystyrene have a characteristic band at $1618 \mathrm{~cm}^{-1}$ corresponding to $\mathrm{C}=\mathrm{C}$ (in plane of $\mathrm{C}_{6} \mathrm{H}_{5}$ ). The characteristic band was found at 3320 and $3380 \mathrm{~cm}^{-1}\left(\mathrm{Ptz}-\mathrm{I}_{2}\right)$ and at $1618 \mathrm{~cm}^{-1}$ (PS) in the composite. This indicates that no chemical interaction is present in the constituents. Hence

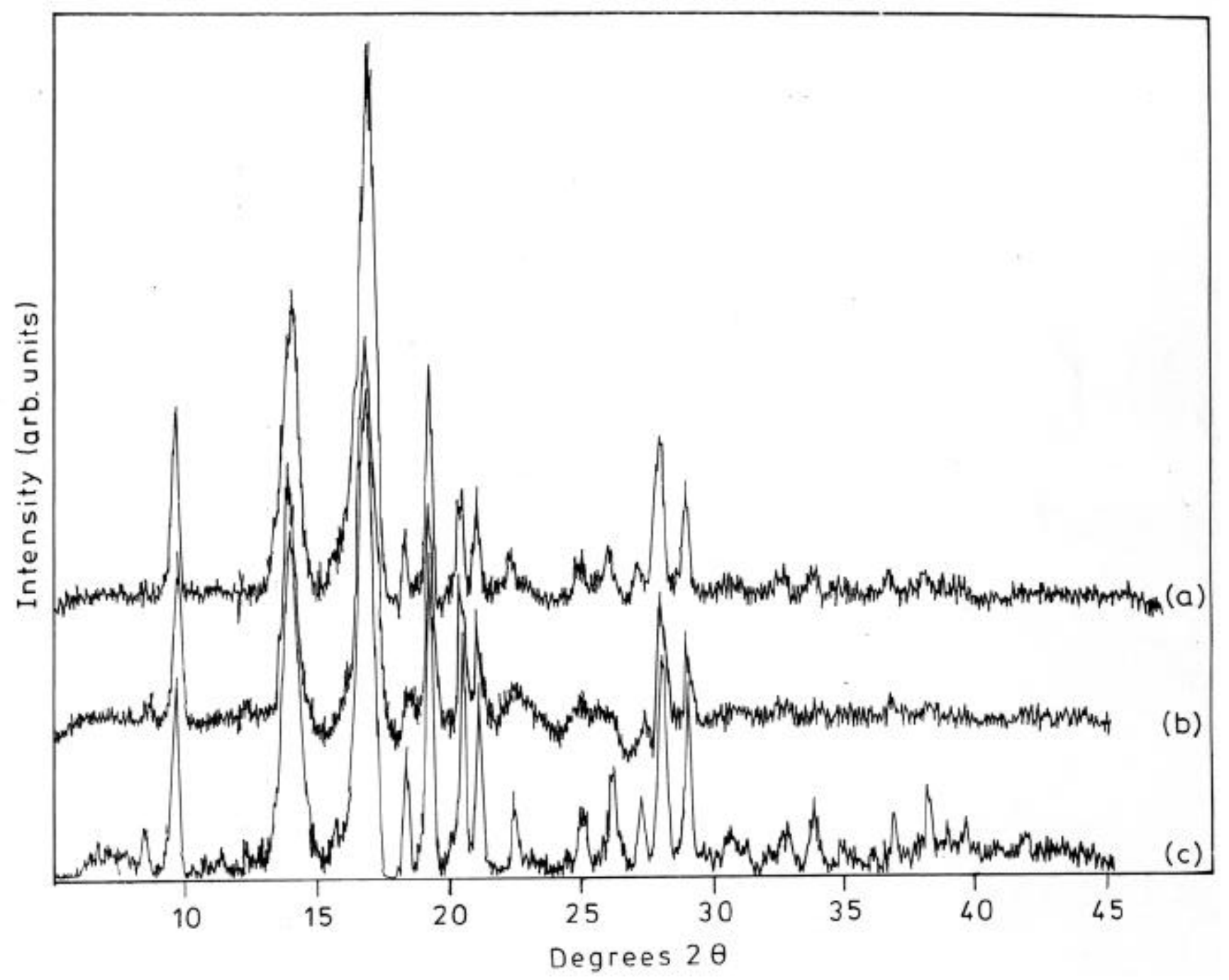

Figure 1. Powder X-ray diffraction pattern of (a) 20\% CTC, (b) $60 \%$ CTC and (c) pure CTC. 
the IR spectra confirm the physical mixture nature of the composites.

The superimposition of the XRD peaks of the composite reveals that the composites are just a physical mixture of their constituent (figure 1), which also confirms that these composites are microcrystals dispersed in the polymer matrix. Polystyrene is amorphous whereas phenothiazineiodine charge-transfer complex shows good crystallinity (Singh et al 1991). The XRD data were analysed by Ito's method (Azaroff and Duerger 1958). The indexing of data shows that phenothiazine-iodine complex has orthorhombic crystal structure, which is retained in the composite as well. The diffraction patterns in composite are due to CTC only, so no diffraction patterns are observed in low percentage compositions. A few of the lattice parameters are given here:

Pure phenothiazine-iodine: $a=5 \cdot 256, b=5 \cdot 297, c=9 \cdot 172$; $60 \mathrm{wt} \%$ CTC: $a=5 \cdot 189, b=5 \cdot 248, c=9 \cdot 007 ; 20 \mathrm{wt} \%$ CTC: $a=5 \cdot 219, b=5 \cdot 270, c=9 \cdot 118$.

These results reveal that the composites are just a physical mixture of the constituents and no chemical interaction is present between them.

\subsection{Mechanical properties}

The compressive strengths of these composites were measured on a pellet of uniform dimensions by taking fixed weight of the materials. The compressive strength of these composites was found to be increasing as the amount of polymer increased (table 1). Pure CTC has a compressive strength of $189.2 \mathrm{~kg} / \mathrm{cm}^{2}$, whereas the $80 \mathrm{wt} \%$ CTC has a compressive strength of $315.4 \mathrm{~kg} / \mathrm{cm}^{2}$, which increases to $540 \cdot 3 \mathrm{~kg} / \mathrm{cm}^{2}$ for $20 \mathrm{wt} \%$ CTC, which was almost comparable to the pure polymer.

\subsection{Electrical properties}

3.3a Direct current studies: The current and voltage characteristics of these composites were studied in the voltage ranges of $\pm 10 \mathrm{~V}$ and were found to be ohmic in nature (figure 2). The values of conductivity vary from

Table 1. Compressive strength of the composites.

\begin{tabular}{lc}
\hline $\begin{array}{l}\text { Percentage of } \\
\text { CTC }(\% \mathrm{wt})\end{array}$ & $\begin{array}{c}\text { Compressive strengths* } \\
\left(\mathrm{kg} / \mathrm{cm}^{2}\right)\end{array}$ \\
\hline Pure PS & $571 \cdot 9$ \\
20 & $540 \cdot 3$ \\
40 & $526 \cdot 4$ \\
60 & $447 \cdot 8$ \\
80 & $315 \cdot 6$ \\
Pure CTC & $189 \cdot 2$ \\
\hline
\end{tabular}

*For the sample of dimension, $A=1.32 \mathrm{~cm}^{2}, l=$ $2 \pm 0 \cdot 2 \mathrm{~cm}$.

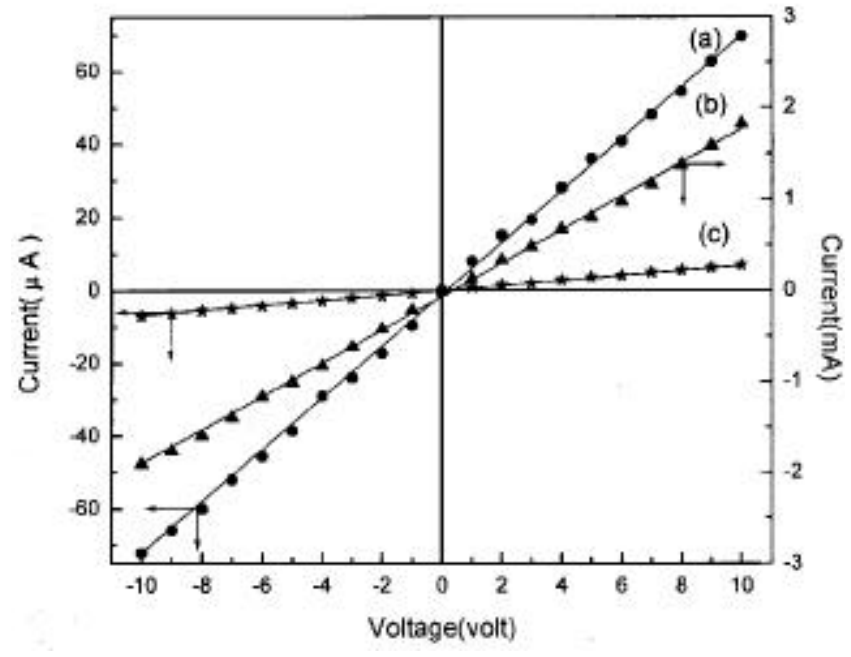

Figure 2. Current-voltage characteristics of phenothiazineiodine-PS (a) $60 \%$ CTC, (b) pure CTC and (c) $20 \%$ CTC.

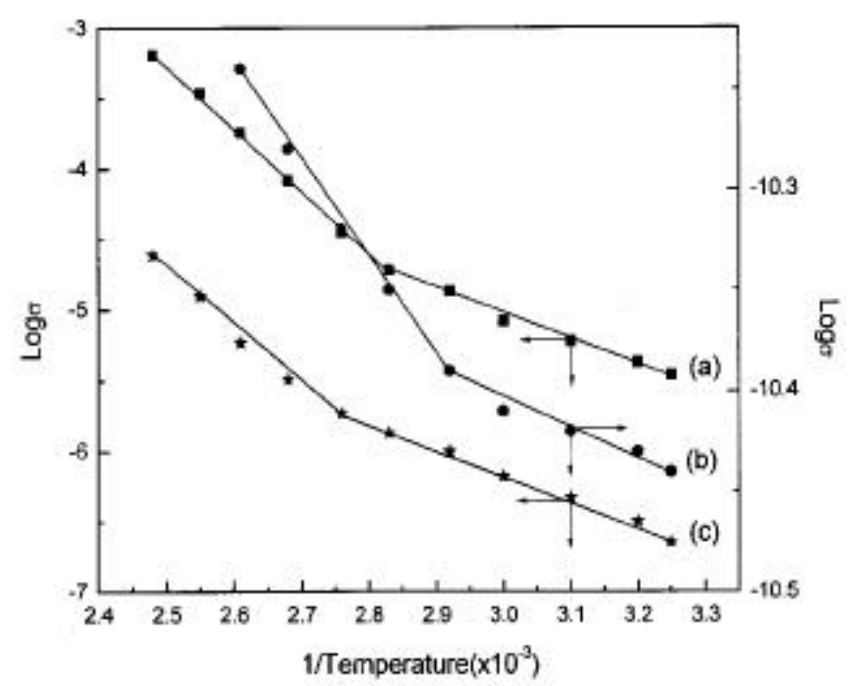

Figure 3. Arrhenius plot for phenothiazine-iodine-PS (a) $80 \%$ CTC, (b) $8 \%$ CTC and (c) $40 \%$ CTC.

Table 2. D.C. electrical properties of phenothiazine-iodinePS composites.

Energy of activation $(\mathrm{eV})$

\begin{tabular}{|c|c|c|c|}
\hline $\begin{array}{l}\text { Percentage of } \\
\text { CTC }(\% \text { wt })\end{array}$ & $\begin{array}{l}\text { Specific conductance } \\
(\mathrm{S} / \mathrm{cm})\end{array}$ & I & II \\
\hline 100 & $3 \cdot 19 \times 10^{-5}$ & 0.49 & 0.44 \\
\hline 80 & $2.67 \times 10^{-6}$ & $0 \cdot 86$ & $0 \cdot 36$ \\
\hline 60 & $1.35 \times 10^{-6}$ & 0.75 & 0.38 \\
\hline 40 & $2.38 \times 10^{-7}$ & 0.81 & 0.37 \\
\hline 20 & $1.40 \times 10^{-7}$ & 0.08 & 0.02 \\
\hline 10 & $3.46 \times 10^{-7}$ & $0 \cdot 10$ & 0.03 \\
\hline 8 & $1.00 \times 10^{-11}$ & 0.09 & 0.03 \\
\hline 6 & $2.69 \times 10^{-12}$ & $0 \cdot 11$ & 0.04 \\
\hline 4 & $2.72 \times 10^{-12}$ & 0.06 & 0.03 \\
\hline
\end{tabular}




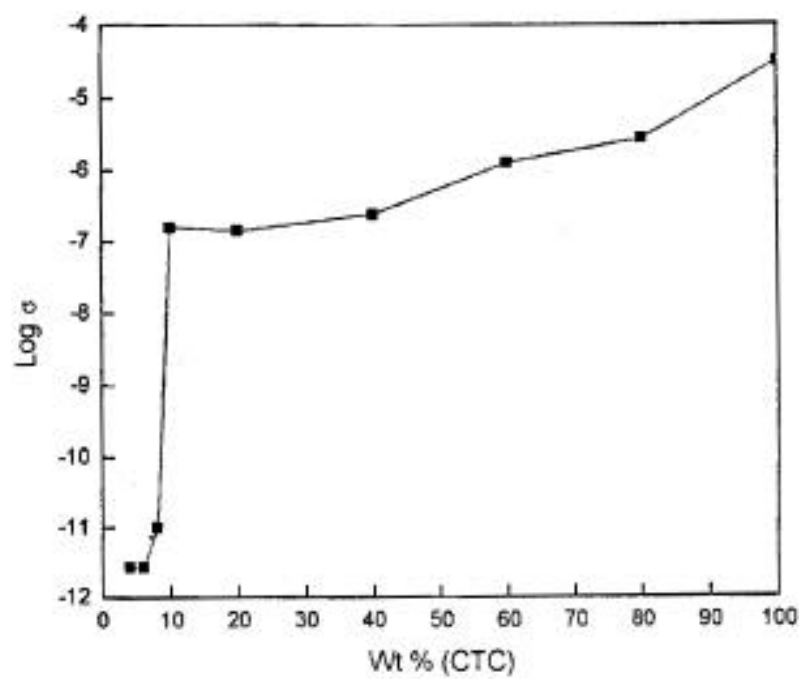

Figure 4. Variation of specific conductance of composite as a function of amount of charge-transfer complex.
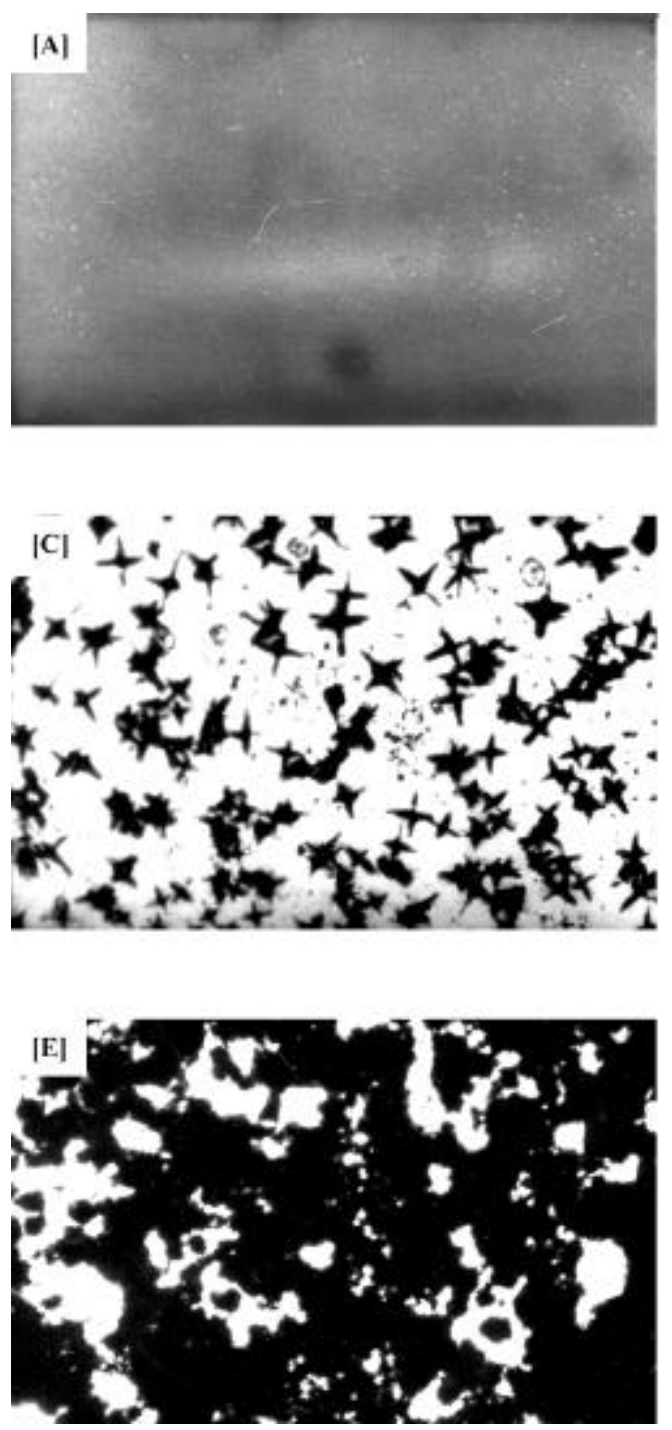

$3.19 \times 10^{-5} \mathrm{~S} / \mathrm{cm}$ (pure CTC) to $2.72 \times 10^{-12} \mathrm{~S} / \mathrm{cm}(4 \%$ CTC composite). The conductivities were also studied as function of temperature in the range 303-393 K. The increase of conductivity with temperature indicates the semiconductive nature of the pure CTC and its composites (figure 3). Two slopes were observed in the Arrhenius plots of these materials indicating the presence of two different types of conduction mechanism in these systems. Similar results have been reported for pure CTC (Singh and Singh 1997). The values of specific conductivities and energy of activations have been calculated and reported in table 2 . The plot of conductivity vs composition (wt $\%$ of CTC), as shown in figure 4 , indicates low percolation threshold $(10 \mathrm{wt} \%)$, which is much higher than the same for reticulately doped polymers with CTC (Ulanski et al 1985). This may be due to different growth mechanisms and microstructures of these composite materials.
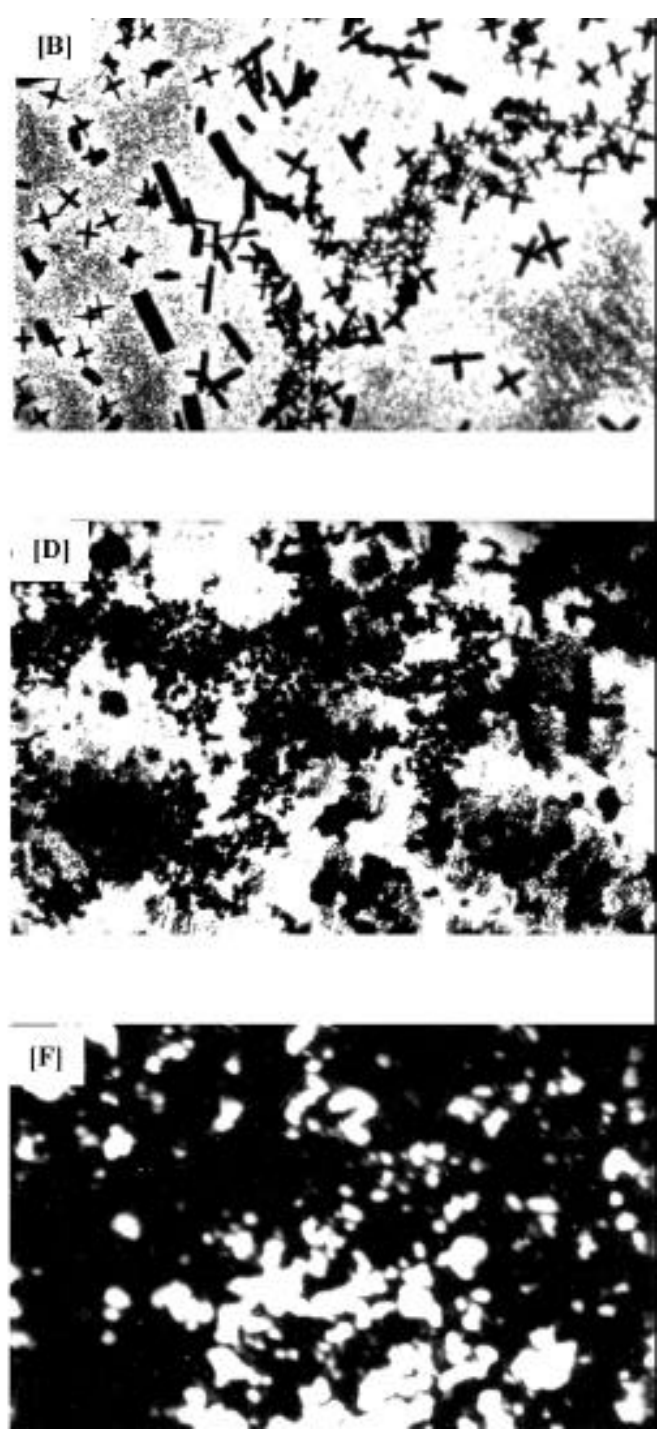

Figure 5. Microphotographs of $[\mathbf{A}]$ pure PS, [B] 2\% CTC, [C] 4\% CTC, [D] 10\% CTC, [E] 40\% CTC and $[\mathbf{F}] 60 \%$ CTC. 
3.3b Alternative current studies: It is clearly seen from the micrographs of the composites that there exist discontinuities in the filler (figure 5). So we expect a frequency dependence of conductivity. We measure the a.c. conductivities using compact pellets of these materials in a pel- let holder made of brass metal using platinum contact in the range $40-10^{5} \mathrm{~Hz}$, and then the data were simulated in the range $10^{-3}-10^{11} \mathrm{~Hz}$ using an EG \& G CNLS fitting software (Manoharan et al 1986). A few representatives of such plots are given in figure 6 .
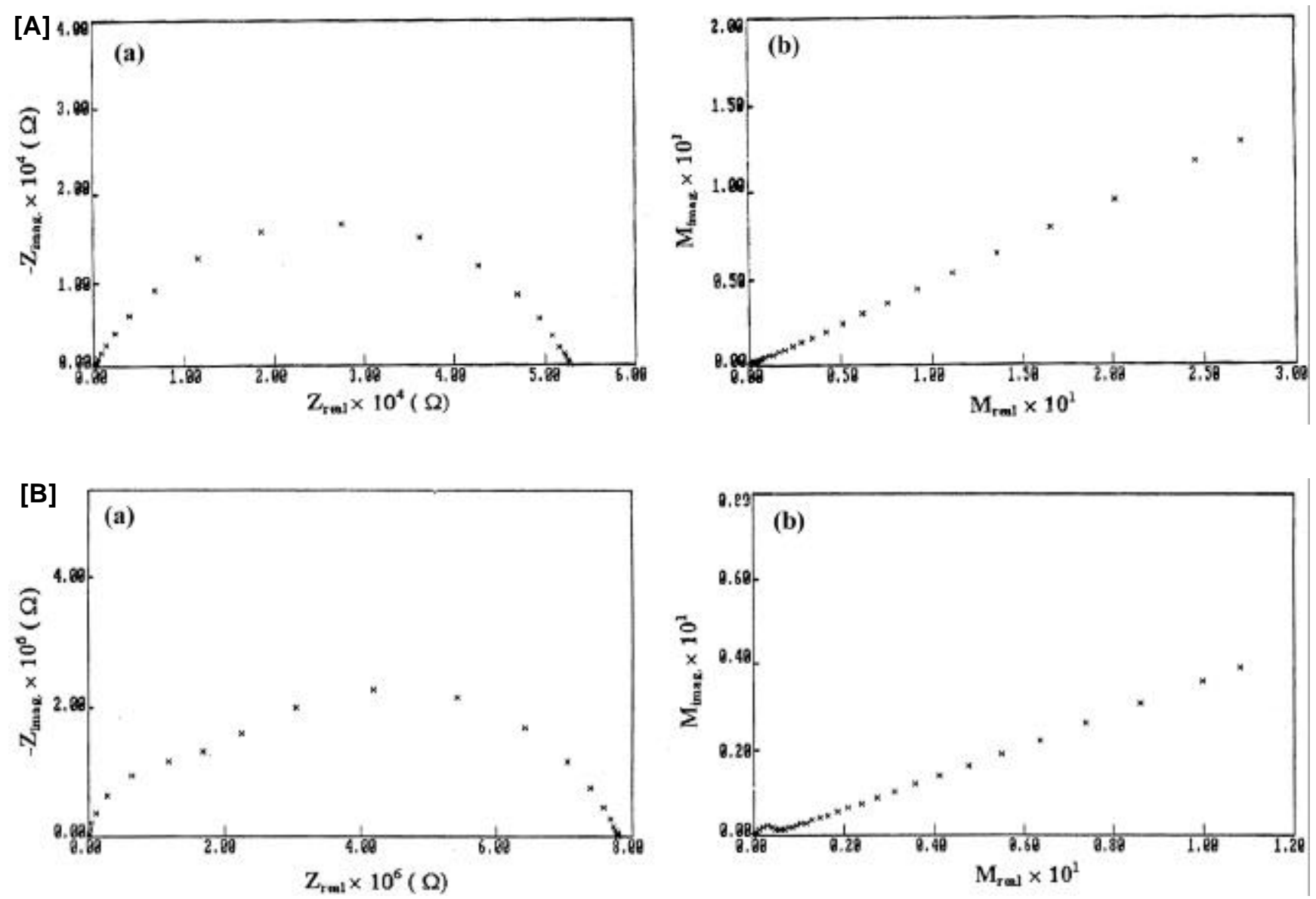

[C]

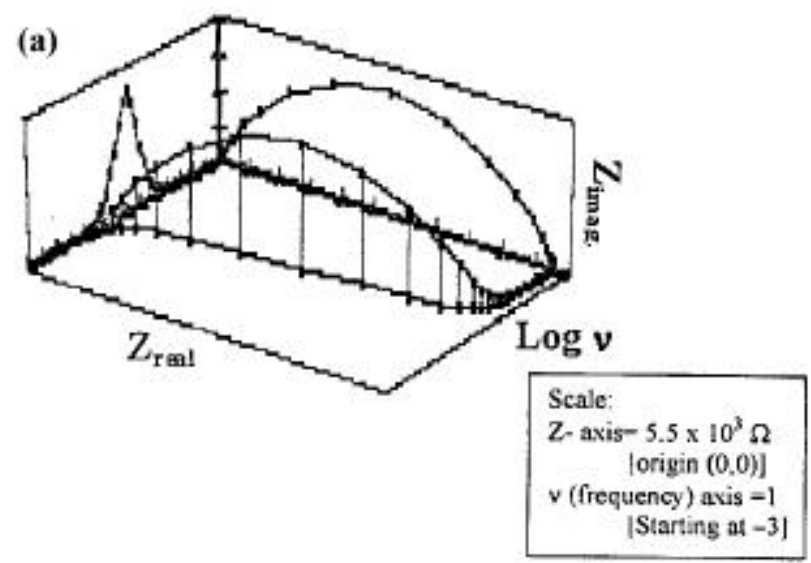

(b)

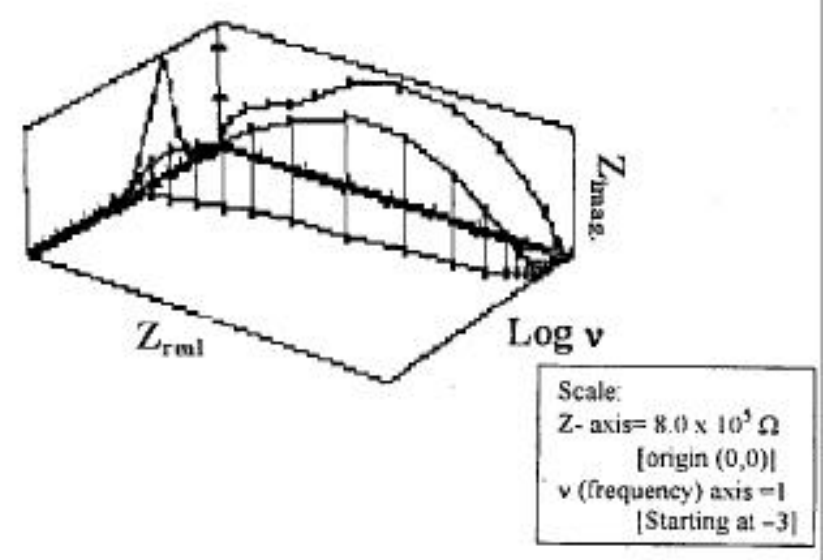

Figure 6. A. Complex immittance plots for phenothiazine-iodine-PS for $60 \mathrm{wt} \%$ CTC composite: (a) complex impedance plot and (b) complex modulus plot, B. complex immittance plots for phenothiazine-iodine-PS for $20 \mathrm{wt} \%$ CTC composite: (a) complex impedance plot and (b) complex modulus plot and C. three-dimensional perspective plots for phenothiazine-iodine-PS: (a) $60 \mathrm{wt} \%$ CTC and (b) $20 \mathrm{wt} \%$ CTC. 
Table 3. Bulk and contact resistance and capacitance separated by a.c. immittance studies for phenothiazine-iodine-PS composites.

\begin{tabular}{|c|c|c|c|c|c|c|c|c|c|}
\hline \multirow[b]{3}{*}{$\begin{array}{l}\text { Percentage of } \\
\text { CTC }(\% \text { wt })\end{array}$} & \multicolumn{9}{|c|}{ Electrical properties } \\
\hline & \multicolumn{3}{|c|}{ Grain } & \multicolumn{3}{|c|}{ Electrode } & \multicolumn{3}{|c|}{ Grain boundary } \\
\hline & $R(\Omega)$ & $\begin{array}{c}Q(\mathrm{Mho}) / \\
C(F)\end{array}$ & $n$ & $R(\Omega)$ & $\begin{array}{c}Q(\mathrm{Mho}) / \\
C(F)\end{array}$ & $n$ & $R(\Omega)$ & $\begin{array}{c}Q(\mathrm{Mho}) / \\
C(F)\end{array}$ & $n$ \\
\hline 100 & $1.86 \times 10^{3}$ & - & - & - & - & - & - & - & - \\
\hline 80 & $2.39 \times 10^{4}$ & $6.43 \times 10^{-10}$ & 0.78 & - & - & - & - & - & - \\
\hline 60 & $5.28 \times 10^{4}$ & $1.41 \times 10^{-9}$ & 0.72 & - & - & - & - & - & - \\
\hline 40 & $2.05 \times 10^{5}$ & $1.23 \times 10^{-10}$ & 0.91 & $1.29 \times 10^{5}$ & $1.65 \times 10^{-7}$ & 0.47 & _- & _- & _ \\
\hline 20 & $6.44 \times 10^{6}$ & $8.89 \times 10^{-10}$ & 0.77 & $1.35 \times 10^{6}$ & $4.80 \times 10^{-11}$ & 0.96 & - & - & _- \\
\hline 10 & $5 \cdot 21 \times 10^{6}$ & $5.74 \times 10^{-10}$ & - & $3.84 \times 10^{6}$ & $9.08 \times 10^{-11}$ & - & $1.88 \times 10^{6}$ & $6.69 \times 10^{-11}$ & 0.91 \\
\hline 8 & $2.63 \times 10^{6}$ & $5.36 \times 10^{-11}$ & - & $6.47 \times 10^{6}$ & $2.69 \times 10^{-10}$ & - & $9.96 \times 10^{5}$ & $1.06 \times 10^{-10}$ & 0.89 \\
\hline 6 & $2.43 \times 10^{6}$ & $1.54 \times 10^{-10}$ & - & $3.38 \times 10^{6}$ & $1.03 \times 10^{-9}$ & _- & $1.32 \times 10^{6}$ & $8.38 \times 10^{-11}$ & 0.89 \\
\hline 4 & $2.93 \times 10^{6}$ & $1.24 \times 10^{-10}$ & - & $4.31 \times 10^{6}$ & $7.29 \times 10^{-10}$ & - & $1.59 \times 10^{6}$ & $1.08 \times 10^{-10}$ & 0.87 \\
\hline
\end{tabular}

Generally we expect the grain, grain boundary and electrode contribution to the overall measured electrical properties. The pure phenothiazine-iodine complex does not show any frequency dependence of a.c. conductivity (Srivastava and Singh 2000). We found only resistive component and no capacitive component for $100 \mathrm{wt} \%$ CTC. The disappearance of capacitive component is due to the fact that no charge accumulates since the sample is highly conductive (Singh and Srivastava 1999). However, all the three expected contributions to the total a.c. electrical conductivities were present in the lower content charge-transfer composites ( $\leq 10 \mathrm{wt} \%$ CTC). As the amount of CTC increases in the composites, the discontinuities gradually reduce due to increased loading and we observe only two arcs viz. grain and electrode. This was actually observed for the compositions from 20-40 wt\% CTC. On further increase of charge-transfer content in the polymer, the electrode contributions were also lost due to large difference in the magnitude of resistances between bulk and electrode. We have found one resistor $(R)$ and one constant phase element $(Q)$ in parallel in 80 and $60 \mathrm{wt} \%$ CTC composites corresponding to the bulk materials and one resistor and one constant phase element (CPE) in parallel connected in series with another resistor and CPE in parallel in 40 and $20 \mathrm{wt} \%$ CTC composites. The a.c. data for all the systems are given in table 3 .

\section{Conclusions}

We prepared polymer composites of phenothiazine-iodine with polystyrene and characterized by a number of techniques. The above study shows that the composite of charge-transfer complexes with insulating polymers could be prepared, which has both good electrical and mechanical properties. These materials could be used for fabrication of solid-state galvanic cells.

\section{Acknowledgements}

The authors are thankful to Dr R K Mandal, Department of Metallurgy, Banaras Hindu University, Varanasi, for recording XRD spectra. One of us (RKG) thanks the Banaras Hindu University, Varanasi, for awarding a research fellowship.

\section{References}

Ashwell G J 1992 Molecular electronics (New York: John Wiley \& Sons Inc.)

Azaroff L V and Duerger M J 1958 The powder method in Xray crystallography (New York: McGraw-Hill)

Benerjee P and Mandal B M 1995 Synth. Metals 47257

Carmono F, Barreau F, Delhaes P and Canet R 1980 J. Phys. Lett. 41 L531

Choi C H, Tracz A, Jeszka J K, Boiteux G, Seytre G, Ulanski J and Kryszewski M 1990 Synth. Metals 37181

Foster R 1969 Organic charge-transfer complexes (New York: Academic Press)

Jeszka J K and Tracz A 1992 Polym. Adv. Technol. 3139

Jeszka J K, Ulanski J and Kryszewski M 1981 Nature 289 390

Kang T J, Miyaki Y, Han J H, Motobe T, Whang Y E and Miyata S 1994 Proc. Pacific Polym. Conf. (New York: SpringerVerlag) 3rd ed., p. 307

Kryszewski M and Jeszka J K 1998 Synth. Metals 9499

Manoharan S P, Birlasekarn S and Suryanarayana C V 1986 Bull. Electrochem. 2509

Margolis J M (ed) 1989 Conducting polymers and plastics (New York: Chapman \& Hall)

Omartova M, Kosina S, Pionteck J, Janke A and Pavlince J 1996 Synth. Metals 8149

Singh R and Singh R A 1997 Mol. Mater. 8187

Singh R A and Srivastava D N 1999 Mol. Mater. 11223

Singh R A, Singh R and Verma S M 1991 Bull. Chem. Soc. Jpn 641938 
Skotheim T A (ed) 1986 Handbook of conducting polymers (New York: Marcel Dekker)

Srivastava D N and Singh R A 2000 Indian J. Phys. A74 335

Tracz A, Jeszka J K, Sroczynska A, Ulanski J and Pakula T 1996 Adv. Matter. Opt. Electron. 6335

Ulanski J 1990 Synth. Metals 3913
Ulanski J, Tracz A and Kryszewski M 1985 J. Phys. D: Appl. Phys. 18451

Yigit S, Hacaloglu J, Akbulut U and Toppare L 1996 Synth. Metals 7911

Yoon C O, Reghu M, Moses D, Heeger A J and Cao Y 1994 Synth. Metals 6347 